\title{
The Free Lunch Is Always an Effective Marketing Tool: Why WIC Must Change
}

\author{
Ted Greiner
}

\section{Dear Editor:}

$\mathrm{C}$ ONGRATULATIONS TO JenSEN and Labbok ${ }^{1}$ and indeed to Breastfeeding Medicine for their article on the impact of the Special Supplemental Nutritional Program for Women, Infants and Children (WIC) on breastfeeding rates in the United States. It provides excellent evidence for the insidious impact of what is in effect a clever and effective formula company profit-making scheme. Who can resist a free lunch?! As Kent ${ }^{2}$ put it, "WIC's breastfeeding promotion efforts are good, but not likely to be of the scale needed. It would take a much larger effort to counteract the strong incentive effect of offering free name-brand infant formula that appears to be endorsed by government."

Jensen and Labbok ${ }^{1}$ also suggest that allowing formula companies to use WIC's name in their marketing serves as a form of endorsement, if unintentional. I saw the remarkable power of this phenomenon in a study in St. Vincent ${ }^{3}$ when I discovered that a group of mothers who passed a Catholic malnutrition rehabilitation facility on their way to work all used the same (unusual) brand that the nuns did. Spying it by looking into the windows, they actually told me they believed the nuns were using it to teach them what they should feed their babies.

As an intern to a public health nutritionist in Silver Spring, MD, I helped design Montgomery County's first WIC application in the summer of 1974 . We heard that the program was saved from oblivion by infant formula company lobbying to Congress. Apparently the companies' market research led them to despair of ever convincing the low-income groups, especially African Americans, to switch from evaporated milk to infant formula. This gave them the ingenious "health" argument that offering free formula was the only way to get low-income U.S. populations weaned off of such a relatively less appropriate means of feeding infants (with, for example, accompanying high levels of infant anemia). Thus warned of the risks involved, we tried reducing them by budgeting so that the value of the food a breastfeeding mother would receive was about double the value of infant formula at that time. Now, of course, the inflation-adjusted price of infant formula is much higher, no doubt linked to the WIC rebates, as Jensen and Labbok ${ }^{1}$ suggest.

But neither we in 1974 nor Jensen and Labbok ${ }^{1}$ came upon the simplest and most powerful way of reducing WIC's anti- breastfeeding impact. Stop offering free formula. The only excuse for offering formula at all is that it is shifting lowincome mothers who may in any case not want to breastfeed from more harmful infant feeding regimens. But, formula does not need to be free to prevent women from raising babies on something inferior. It just needs to be the cheapest alternative available.

In 1978-1981, I designed and evaluated a Rockefeller Foundation-funded breastfeeding promotion program in Yemen for my Ph.D. research. ${ }^{4}$ I spent one entire year obtaining baseline data and working with anthropologists and health workers to try understanding why breastfeeding had declined so rapidly during the previous few years. A wise Swedish midwife working in a Maternal Child Health center there helped me with one strand of the causal web. She said that Yemeni women had nothing against breastfeeding. They just saw the decision to switch to the bottle as unimportant- each feeding method had its advantages and disadvantages. Thus one goal of the later campaign (which set in motion processes that led gradually to a doubling of the duration of breastfeeding in both rural and urban areas of the country) was not so much to say that women ought to breastfeed as to help them realize that deciding to supplement in the early months or to stop it in the first couple years was a serious one-especially in a country where only $2 \%$ of couples practiced any form of modern contraception. (The qualitative "illuminative evaluation" found that most women who did practice exclusive breastfeeding were doing it because they were tired of having a baby every year.)

As it stands now, many WIC mothers probably think similarly, if they think much about breastfeeding at all-or they abandon it at the first sign of difficulty-because accepting free formula is such an easy alternative into which to slide. If the WIC formula has a cost, even if low, then it is more likely that low-income women will go through some kind of weighing of the alternatives before making decisions so crucial to their own and their infants' health.

\section{References}

1. Jensen E, Labbok M. Unintended consequences of the WIC formula rebate program on infant feeding outcomes: Will the new food packages be enough? Breastfeed Med 2011;6:145-149.

Department of Food and Nutrition, Hanyang University, Seoul, Korea. 
2. Kent G. WIC's promotion of infant formula in the United States. Int Breastfeed I 2006;20;1:8.

3. Greiner T, Latham MC. Infant feeding practices in St. Vincent and factors which affect them. West Indian Med J 1981; 30:8-16.

4. Greiner T. The Planning, Implementation and Evaluation of a Project to Protect, Support and Promote Breastfeeding in the Yemen Arab Republic [Ph.D. thesis]. Cornell University Division of Nutritional Sciences, Ithaca, NY, 1983.
Address correspondence to: Ted Greiner, Ph.D.

Department of Food and Nutrition Hanyang University 17 Haengdang-dong, Seongdong-gu Seoul 133-791, Korea

E-mail: tgreiner@hanyang.ac.kr; tedgreiner@yahoo.com 
This article has been cited by: 